\title{
Ethylene Polymerization over Metal-Organic Framework Crystallites and the Influence of Linkers on Their Fracturing Process
}

Miguel Rivera-Torrente, ${ }^{\dagger}$ Paul D. Pletcher, ${ }^{\dagger}$ Maarten K. Jongkind, Nikolaos Nikolopoulos, and Bert M. Weckhuysen*(1)

Inorganic Chemistry and Catalysis, Debye Institute for Nanomaterials Science, Utrecht University, Universiteitsweg 99, 3584 CG Utrecht, The Netherlands

Supporting Information

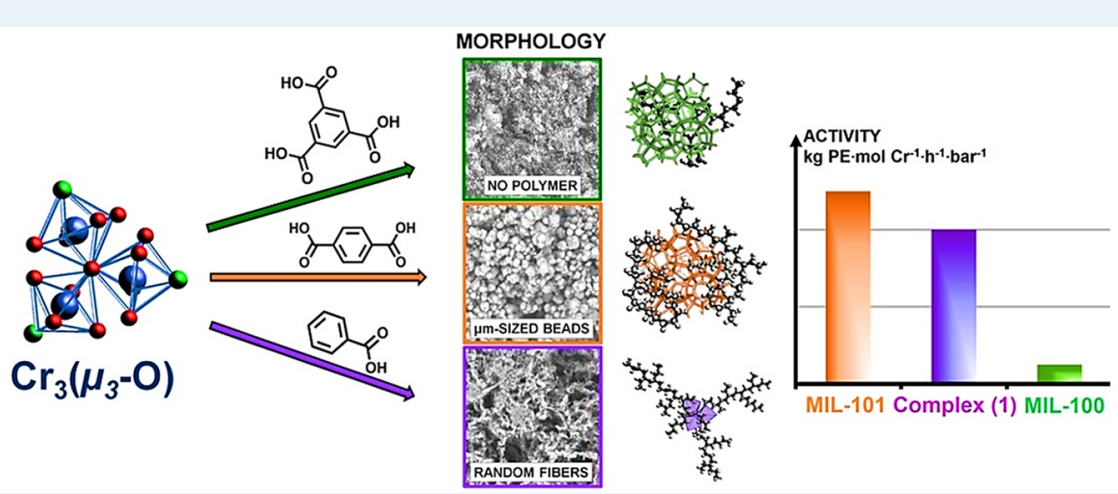

ABSTRACT: The physical properties and morphologies of polymers are pivotal for their manufacturing and processing at the industrial scale. Here, we present the formation of either fibers or micrometer-sized polyethylene beads by using the MIL$100(\mathrm{Cr})$ and MIL-101(Cr) zeotypes. The MOF structures have been used for ethylene polymerization with diethylaluminum chloride (DEA) as a cocatalyst, resulting in very different activities and morphologies. In situ DR UV-vis-NIR and CO-probe FT-IR spectroscopy revealed the formation of different types of $\mathrm{Cr}$ species for each catalyst material, suggesting that the linker (for the same metal and topological structure) plays a crucial role in the formation of Cr olefin polymerization sites. Activity in ethylene polymerization in toluene at $10 \mathrm{bar}$ and $298 \mathrm{~K}$ was related to the observed spectra, corroborating the presence of different types of active sites, by their different activities for high-density polyethylene (HDPE) formation. SEM micrographs revealed that although MIL-100 and MIL-101 exhibit identical zeolitic MTN topology, only the latter is able to collapse upon addition of DEA and subsequent ethylene insertion and to fracture forming polymer beads, thus showing noticeable activity in HDPE formation. We ascribed this effect to the higher pore volume and, thus, fragility of MIL-101, which allowed for polymer formation within its larger cages. MOFs were compared to the nonporous chromium(III) benzoate $\left[\mathrm{Cr}_{3} \mathrm{O}\left(\mathrm{O}_{2} \mathrm{CPh}\right)_{6}\left(\mathrm{H}_{2} \mathrm{O}\right)_{2}\right]$ $\left(\mathrm{NO}_{3}\right) \cdot n \mathrm{H}_{2} \mathrm{O}$ complex (1), in order to study the effect of the embodiment in the porous framework. The properties of the polymer obtained under identical reaction conditions were comparable to that of MIL-101 $(\mathrm{Cr})$ but very different morphologies were observed, indicating that the MIL-101(Cr) structure is necessary to impart a certain architecture at the microscale. This work clearly shows that MOFs can be used as catalytically active morphology regulators for ethylene polymerization. Moreover, even for an identical topology and metal in a MOF structure, the linker and the pore structure play crucial roles and have to be carefully considered in the design microporous coordination polymers for catalytic purposes.

KEYWORDS: in situ UV-vis spectroscopy, ethylene polymerization, catalyst characterization, heterogeneous catalysis, MIL-100(Cr), MIL-101(Cr), metal-organic frameworks

\section{INTRODUCTION}

Polyethylene (PE) production has been estimated to reach 100 million tons per year by 2020 and will continue to be an ubiquitous material for our modern society in the decades to come. A wide variety of reactor configurations (i.e. liquid, slurry, and gas phase) and catalyst materials (metallocene, Ziegler-Natta, and Phillips) are used for its production depending on the required physicochemical properties, such as density, melting point, and viscosity as well as morphology, ${ }^{1}$ that need to be conferred to the polymer for further processing. ${ }^{2-4}$ In order to alter the architecture of the polymer at the macroscale, different systems in which the support plays the role of a "cast" have been used in the past. Examples of such efforts include the so-called extrusion polymerization in which the active olefin polymerization sites have been incorporated in the family of MCM-41 and SBA-15

Received: January 12, 2019

Revised: February 21, 2019

Published: March 11, 2019 
mesoporous materials, yielding polyethylene microcrystalline fibers. ${ }^{5-10}$

Metal-organic frameworks (MOFs) are another interesting class of porous materials that have been recently used for polymer templating. ${ }^{11-17}$ MOFs consist of coordination networks with organic ligands connected to metal nodes or cations, containing potential voids upon guest molecule removal. ${ }^{18}$ Their well-defined metal sites, together with their porosity, have fostered their use as single-site porous catalysts. ${ }^{19-21}$ Indeed, a number of MOFs have been studied as solid catalysts for the polymerization and oligomerization of short olefins, due to their industrial relevance and relatively mild conditions required for operation, together with the necessity of fine-tuning selectivity. ${ }^{22-26}$ Ethylene oligomerization (in both the liquid ${ }^{27}$ and the gas phase ${ }^{28-33}$ ) and polymerization, ${ }^{34-37}$ as well as propylene dimerization in the gas phase, ${ }^{38-40}$ or even isoprene polymerization, ${ }^{41}$ can be catalyzed by a number of MOFs, postsynthetic modification being necessary in most cases. However, despite its paramount importance in later applications, polymer morphology has been often overlooked and most of the MOF-based catalyst materials described often show either poorly or nonshaped materials. Recently, Liu et al. $^{42}$ reported on the selective oligomerization of ethylene by the chromium nodes of MIL$100(\mathrm{Cr})$ after activation with organoaluminum species, wherein the activity and selectivity can be tuned by simple thermal treatments without the need for additional modifications on the MOF framework. Their work has inspired our efforts in investigating the possibilities of MIL-100(Cr) materials for olefin polymerization. MIL- $100(\mathrm{Cr})^{43}$ and MIL$101(\mathrm{Cr})^{44}$ frameworks (where MIL stands for Matériau de l'Institut Lavoisier) are among the most studied MOFs due to their high porosity $\left(S_{\mathrm{BET}} \approx 1500-3000 \mathrm{~m}^{2} / \mathrm{g}\right)$, tunability, and chemical and hydrothermal stability.

In this work, we have taken advantage of the ability of MIL$101(\mathrm{Cr})$, in contrast to the more solid MIL-100(Cr) and the homogeneous $\mathrm{Cr}$ complex $\left[\mathrm{Cr}_{3} \mathrm{O}\left(\mathrm{O}_{2} \mathrm{CPh}\right)_{6}\left(\mathrm{H}_{2} \mathrm{O}\right)_{3}\right]\left(\mathrm{NO}_{3}\right)$. $n \mathrm{H}_{2} \mathrm{O}(\mathbf{1})$, to fracture upon addition of a strongly oxophilic organoaluminum activator and subsequent ethylene polymerization in the liquid phase. Moreover, we sought to understand the effects of the cocatalysts when they are used in combination with these MOF materials, as well as the reaction conditions, by means of in situ spectroscopy together with a detailed analysis of the polymer products formed. We will show that even for an identical pore structure and metal in a MOF, the organic linker plays a crucial role and has to be chosen specifically to obtain targeted polyolefin polymer products.

\section{EXPERIMENTAL SECTION}

2.1. Catalyst Preparation. The synthesis of the coordination complex 1, MIL-100(Cr), and MIL-101(Cr) was carried out according to previously published procedures. ${ }^{43-45}$ Details on the preparation and routine characterization of the materials can be found in the Supporting Information.

2.2. Material Characterization. X-ray diffraction (XRD) patterns were obtained with a Bruker-AXS D2 Phaser powder $\mathrm{X}$-ray diffractometer in Bragg-Brentano geometry, using Co $\mathrm{K} \alpha_{1,2}=1.79026 \AA$, operated at $30 \mathrm{kV}$. The measurements were carried out between 2 and $30^{\circ}$ using a step size of $0.05^{\circ}$ and a scan speed of $1 \mathrm{~s}$, with a $0.1 \mathrm{~mm}$ slit for the source. Simulated $\mathrm{XRD}$ patterns were obtained by processing the corresponding .cif files with VESTA $(\lambda=1.79026 \AA$, fwhm $=0.2)$ from refs 43 and 46.

$\mathrm{N}_{2}$ adsorption isotherms were measured at $77 \mathrm{~K}$ on a Micromeritics TriStar 3000 instrument. Prior to all measurements, samples were dried at $423 \mathrm{~K}$ under dynamic vacuum. Specific surface areas (SSAs) were calculated using the multipoint BET method $\left(0.05<p / p_{0}<0.25\right)$. Pore volumes $\left(V_{\mathrm{p}}\right)$ were calculated by the $t$-plot method; pore size distributions (PSDs) were obtained by DFT using $\mathrm{N}_{2}$ and spherical pores in the package MicroActive 4.06 (Micromeritics).

Fourier transform infrared (FT-IR) spectroscopy measurements at $85 \mathrm{~K}$ were recorded with a PerkinElmer 2000 instrument, in a specially designed cell fitted with $\mathrm{CaF}_{2}$ windows. The degassed (at $423 \mathrm{~K}$ ) MOF materials studied were pressed into 3-5 $\mathrm{mg}$ wafers inside of a glovebox and fitted into the FTIR cell. The cell was sealed, connected to the gas/vacuum system, and carefully evacuated to $\sim 10^{-5} \mathrm{mbar}$ at 298 K. A $10 \% \mathrm{CO} / 90 \% \mathrm{He}(\mathrm{v} / \mathrm{v})$ mixture was slowly introduced into the cell until the pressure reached $250 \mathrm{mbar}$ and allowed to equilibrate. The sample was then cooled using liquid nitrogen (to $85 \mathrm{~K}$ ) to allow the $\mathrm{CO}$ to saturate and equilibrate on the surface. The cell gas pressure was decreased, and spectral measurements were taken after the pressure stabilized. A final measurement was taken after outgassing the cell for $20 \mathrm{~min}$. To measure the CO FT-IR spectra of the sample activated at $623 \mathrm{~K}$, the cell was slowly warmed to $298 \mathrm{~K}$ under vacuum and then heated to $623 \mathrm{~K}$ at a rate of $5 \mathrm{~K} \mathrm{~min}^{-1}$ and maintained at $623 \mathrm{~K}$ for $1 \mathrm{~h}$. The sample was then cooled to room temperature, and the previously described CO FT-IR measurement protocol was used to probe the surface acidity. For the $\mathrm{Et}_{2} \mathrm{AlCl}$ (DEA, Sigma-Aldrich, 97\%) activated samples, $\sim 20 \mathrm{mg}$ of MOF material was mixed with 100 equiv of DEA for $20 \mathrm{~min}$ in the glovebox. The solvent was decanted and the remaining solid dried under vacuum. Then, $\sim 5 \mathrm{mg}$ of material was then pressed into a pellet and the CO FT-IR spectroscopy measurements were carried out by following the previously described measurement protocol.

UV-vis-NIR diffuse reflectance spectroscopy (UV-visNIR DRS) measurements were performed under in situ conditions by making use of a Varian Cary 500 spectrophotometer with a DRS accessory. The measurements were performed in the spectral range of $4000-45000 \mathrm{~cm}^{-1}$ with 33 $\mathrm{ms}$ data point scan time and spectral resolutions of 17 and 7 $\mathrm{cm}^{-1}$, in the $12500-45000$ and $4000-12500 \mathrm{~cm}^{-1}$ spectral ranges, respectively. Two artifacts in the measured spectra were corrected for the detector/grating and light source changeovers at 12500 and $28570 \mathrm{~cm}^{-1}$, while the spectral feature appearing at $11250 \mathrm{~cm}^{-1}$ is due to an instrument artifact. For every measurement, the cell was loaded in a $\mathrm{N}_{2}$-filled glovebox $(<2$ ppm of $\mathrm{H}_{2} \mathrm{O}, \mathrm{O}_{2}$ ), thereby keeping the samples from contact with atmospheric oxygen and water. The samples were measured against a Teflon-white measured in the same cell loaded with the same volume of $30 \mu \mathrm{m}$ beads of Teflon powder. For measurement of the materials, $100 \mathrm{mg}$ of catalyst material was loaded in a homemade cell. Subsequently, the required amounts of DEA were injected under a $\mathrm{N}_{2}$ flow of 10 $\mathrm{mL} \mathrm{min}^{-1}$. After injection, the spectra were recorded until no further spectral changes were observed. Subsequently, the gas

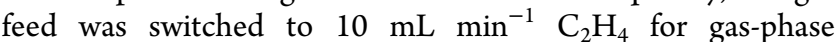
polymerization (Linde $\mathrm{AG}, \mathrm{C}_{2} \mathrm{H}_{4}, 99.9 \%$ ). Spectra were recorded until no further changes occurred. 
Scanning electron microscopy (SEM) micrographs of the MOF crystallites and the MIL-100(Cr) after reaction were recorded on a FEI Helios nanolab 600 Dual Beam with an Oxford Instruments Silicon Drift Detector X-Max energydispersive spectroscope. After the sample was deposited onto Al stabs with carbon tape (Electron Microscopy Sciences, Hartfield, PA, USA), the samples were sputtered with $22 \mathrm{~nm}$ of $\mathrm{Pt}(-\mathrm{Pd})$. Thereafter, imaging and EDX analysis were carried out at a beam of $15 \mathrm{kV}$ and $0.1 \mathrm{nA}$. Micrographs of the polymer samples were recorded on a PhenomPro $\mathrm{X}$ microscope (FEI Company, USA), equipped with a CsB detector for backscattered electrons (BSE), operated at $10 \mathrm{kV}$. The samples were mounted on holey carbon tape supported on $\mathrm{Al}$ stubs that were not coated prior to measurements.

Differential scanning calorimetry (DSC) analyses were done with ca. 3-4 mg of polymer; each run was analyzed using a Texas Instrument Discovery DSC featuring an automatic sampler and TRIOS software. Each sample was heated from 298 to $473 \mathrm{~K}$ at a rate of $10 \mathrm{~K} \mathrm{~min}^{-1}$, held at $473 \mathrm{~K}$ for $2 \mathrm{~min}$ to erase the thermal history, and then cooled to $313 \mathrm{~K}$ at $1 \mathrm{~K}$ $\mathrm{min}^{-1}$ to ensure a slow recrystallization of the polymer. A second heating ramp was used to determine the melting temperature $\left(T_{\mathrm{m}}\right)$ and enthalpy $\left(\Delta H_{\mathrm{m}}\right)$, in which the sample was heated at $10 \mathrm{~K} \mathrm{~min}^{-1}$ to $473 \mathrm{~K}$, before being cooled back to $298 \mathrm{~K}$. The crystallinity of the polymer samples was determined assuming $\Delta H_{\mathrm{m}}{ }^{0}=293 \mathrm{~J} / \mathrm{g}$, for $100 \%$ crystalline ultrahigh-molecular-weight polyethylene (UHMWPE).

Gel permeation chromatography (GPC) was carried out on a Polymer Laboratories PL-GPC220 instrument, equipped with a PL BV-400 refractive index detector. The column set consisted of three Polymer Laboratories $13 \mu \mathrm{m}$ PLgel Olexis $300 \times 7.5 \mathrm{~mm}$ columns, and the calibration was performed with linear polyethylene (PE) and polypropylene (PP) standards. PP molar mass calibration was obtained after conversion from $\mathrm{PE}$ to $\mathrm{PP}$ using the Mark-Houwink constants.

2.3. Catalytic Testing. The degassed MOFs and complex 1 were tested for the polymerization of ethylene at 10 bar in the liquid phase. For the runs, $5 \times 10^{-2} \mathrm{mmol}$ of catalyst was introduced into a stainless-steel Parr reactor, together with $\mathrm{Al}$ :Cr ratio molar ratios of 100,500 , or 1000 of DEA in toluene (Sigma-Aldrich, anhydrous, 99.8\%) inside an Ar-filled glovebox $\left(\mathrm{O}_{2}, \mathrm{H}_{2} \mathrm{O}<2 \mathrm{ppm}\right)$. The autoclave was connected to an ethylene (Linde AG, 99.9\%) line, the system was evacuated and flushed with ethylene three times before the cell was pressurized to 10 bar at $298 \mathrm{~K}$, and the mixture was mechanically stirred at $1000 \mathrm{rpm}$. The cell was depressurized of ethylene after $1 \mathrm{~h}$ of reaction, the autoclave was cooled to $195 \mathrm{~K}$ using an acetone/dry ice bath, and the pyrophoric materials were quenched using acidified (37 wt \% $\mathrm{HCl}(\mathrm{aq})$, Merck KGaA) methanol. The solid polyethylene was filtered, rinsed with $\mathrm{MeOH}$ (98\%, VWR International), and dried under high vacuum overnight. The catalyst activity was based on the weighed polymer product.

\section{RESULTS AND DISCUSSION}

MIL-100(Cr) and MIL-101(Cr) frameworks are built up with chromium cations in an octahedral coordination forming the so-called chromium oxo-bridged trimer units, i.e. $\left[\left(\mathrm{Cr}_{3}\left(\mu_{3}-\right.\right.\right.$ $\mathrm{O})]$, bonded to trimesic acid $\left(\mathrm{H}_{3} \mathrm{BTC}\right)$ or terephthalic acid $\left(\mathrm{H}_{2} \mathrm{BDC}\right)$ for MIL-100(Cr) or MIL-101(Cr), respectively. Coordinatively unsaturated positions (CUS) on the $\mathrm{Cr}^{3+}$ cations can be generated by removing the ligand in the axial position (typically nitrate, halide, hydroxy, or carboxylate anions arising from the synthesis) upon thermal treatment of the solid under vacuum. ${ }^{47}$ In order to be able to solely compare the effects of MOF topology and exclude the presence of residual potential poisons, we carried out an anion exchange with $\mathrm{Cl}^{-}$ions. Although the structure exhibits well-defined $\mathrm{Cr}^{3+}$ ions, the nature of the metal active sites upon addition of alkylating agents, such as diethylaluminum chloride (DEA), is not well understood. In order to verify that, isoreticular MIL-100(Cr) and MIL-100(Cr) were prepared following standard protocols and their crystallinity, purity, porosity, and morphology confirmed by means of X-ray diffraction (XRD), $\mathrm{N}_{2}$ adsorption at $77 \mathrm{~K}$, thermogravimetric analysis (TGA), and scanning electron microscopy (SEM) (Sections $1-5$ in the Supporting Information), respectively. The materials were subsequently impregnated with DEA and studied by XRD.

3.1. Structural Stability and Active Sites. XRD patterns of the materials after reaction with DEA, contact with ethylene at $298 \mathrm{~K}$, and subsequent gentle quenching in air were obtained in order to study the stability of the MOFs upon contact with the cocatalyst. For this purpose, ca. $10 \mathrm{mg}$ of activated MIL-100(Cr) and MIL-101(Cr) was mixed with DEA in an Ar-filled cell. Then, a $2 \mathrm{~mL} \mathrm{~min}^{-1}$ stream of air was flowed for $30 \mathrm{~min}$ at $298 \mathrm{~K}$ through the cell to quench any unreacted organoaluminum species. In Figure 1a, it can be
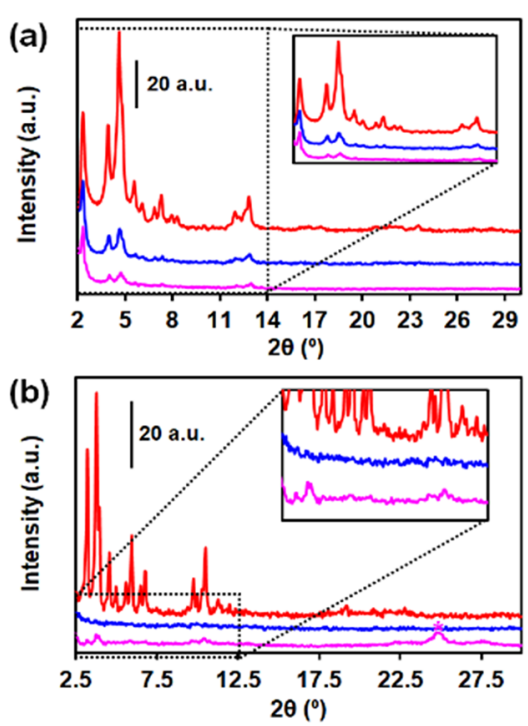

Figure 1. XRD patterns of (a) MIL-100(Cr) and (b) MIL-101(Cr) as synthesized (red), after contact with 125 equiv of DEA $(\mathrm{Al}: \mathrm{Cr}=100)$ (blue), and after ethylene was flowed at $298 \mathrm{~K}$ for $15 \mathrm{~min}$ (pink). The asterisk $(*)$ indicates the formation of some high-density polyethylene (HDPE). Insets show the area with the main XRD reflections of the crystalline MOF.

seen that although the material is diffracting X-rays less intensely, the main XRD peaks at $2.36,3.97,4.64$, and $4.89^{\circ}$, corresponding to the (220), (311), (222), and (400) reflections, respectively, are still present, indicating that the MOF structure is partially retained. Even after ethylene was flowed through the cell, the material did not show significant changes or the presence of a polymeric material. In contrast, the XRD patterns in Figure $1 \mathrm{~b}$ show that the reaction of MIL$101(\mathrm{Cr})$ with DEA resulted in a complete loss in crystallinity, 

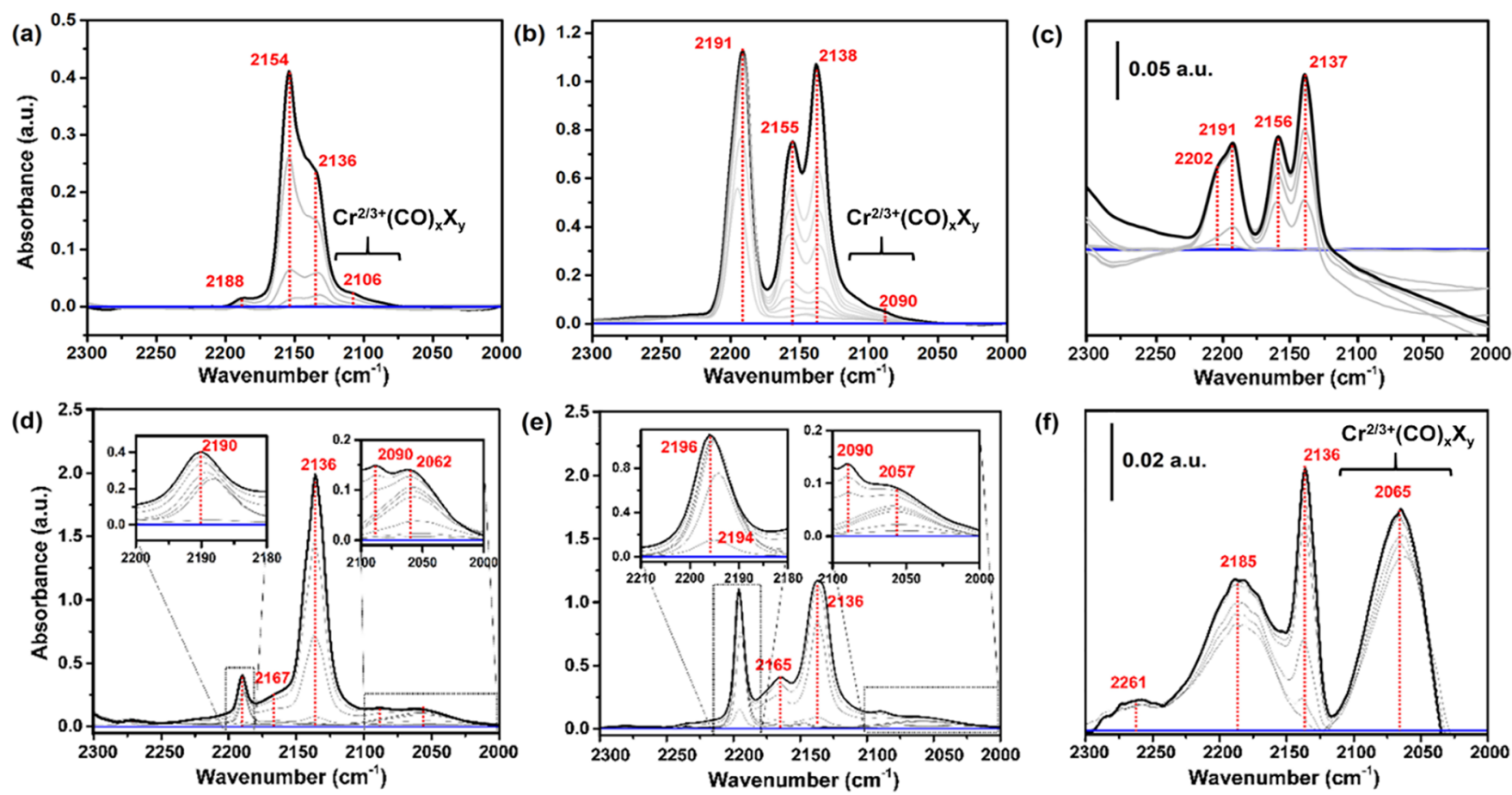

Figure 2. FT-IR spectra with $\mathrm{CO}$ as a probe molecule measured at $85 \mathrm{~K}$ of $(\mathrm{a}-\mathrm{c}) \mathrm{MIL}-100(\mathrm{Cr})$ and $(\mathrm{d}-\mathrm{f}) \mathrm{MIL}-101(\mathrm{Cr})$ after activation under vacuum $\left(10^{-5} \mathrm{mbar}\right)$ for $16 \mathrm{~h}$ at $423 \mathrm{~K}$, at $623 \mathrm{~K}$, and after impregnation with diethylaluminum chloride (DEA) (with Al:Cr molar ratio 100) and CO dosage (0-1 mbar) at $85 \mathrm{~K}$. Degassed MIL-100(Cr) was subtracted as a reference in (b) and (c). MIL-101(Cr) was subtracted as a reference spectrum in (e) and (f).

as none of the main reflections are present and only an amorphous pattern remains.

This observation can be explained by a cleavage of the $\mathrm{Cr}-$ $\mathrm{O}$ bonds by the cocatalyst, resulting in the formation of defects, reduced and alkylated $\mathrm{Cr}$, and linker sites as well as alumina or aluminum oxide like species. When ethylene was passed through the cell, a white solid, which was confirmed to be traces of HDPE (Supporting Information, Section S6 and Figure S11) appeared. This demonstrated that some of the $\mathrm{Cr}$ sites are able to form a polymer in the gas phase, unlike the case for the MIL-100(Cr) structure.

In order to understand if different $\mathrm{Cr}$ sites were present in the MOF frameworks after degassing and upon addition of DEA, in situ FT-IR spectroscopy experiments with $\mathrm{CO}$ as a probe molecule were carried out. In line with the literature, different types of sites were observed when the material was dried at 423 or $623 \mathrm{~K}^{47}$ First of all, in Figure $2 \mathrm{a}-\mathrm{c}$, spectra of MIL-100(Cr) dosed with CO show the presence of very few coordinatively unsaturated sites $\left[\mathrm{Cr}^{3+} \ldots \mathrm{CO}\right]$ when degassing was done at $423 \mathrm{~K}$ (at $2188 \mathrm{~cm}^{-1}$ ). A very intense band at $2154 \mathrm{~cm}^{-1}$ (next to that at $2136 \mathrm{~cm}^{-1}$ of physisorbed CO) indicates that most sites were still hydroxylated. Interestingly, a small feature at $2106 \mathrm{~cm}^{-1}$ was observed, which may correspond to the formation of extraframework or defectively coordinated $\mathrm{Cr}$ cations during synthesis or degassing. We tentatively ascribe this feature to partially reduced $\mathrm{Cr}^{3+/ 2+}(\mathrm{CO})_{x} \mathrm{X}_{y}\left(\mathrm{X}=\mathrm{Cl}^{-}, \mathrm{NO}_{3}, \mathrm{OH}^{-}\right.$, or $\left.\mathrm{H}_{2} \mathrm{BTC}^{-}\right)$species, as they are typically present at such low wavenumber regions. $^{48-52}$

The presence of the main interaction $\mathrm{OC} \cdots \mathrm{Cr}^{3+}(\mathrm{MOF})$ bands at $2200-2180 \mathrm{~cm}^{-1}$ makes it impossible to distinguish the presence of $\mathrm{Cr}^{2+}$ sites by using this region. This feature is observed at $2090 \mathrm{~cm}^{-1}$ when the sample is degassed at $623 \mathrm{~K}$, indicating that indeed the treatment has a certain effect on the coordination environment of the $\mathrm{Cr}$ cations. Moreover, the band at $2188 \mathrm{~cm}^{-1}$ is slightly shifted toward $2191 \mathrm{~cm}^{-1}$ and is much more intense, indicating that a much larger number of Lewis acid $\mathrm{Cr}^{3+}$ sites appear upon degassing at higher temperature. Addition of the organo-aluminum compound results in a strong modification of the baseline as well as in the formation of a shoulder at $2200 \mathrm{~cm}^{-1}$, which indicates an abstraction of additional counterions from the $\mathrm{Cr}$ sites. No further indications of the presence of $\mathrm{Cr}^{2+}$ sites are present, suggesting that they are alkylated and are not available for binding with $\mathrm{CO}$ as probe molecule. When an identical treatment was carried out on MIL-101(Cr), a number of differences were observed. First of all, when the material was degassed at $423 \mathrm{~K}$, a higher fraction of Lewis $\mathrm{Cr}^{3+}$ sites was observed as a band at $2190 \mathrm{~cm}^{-1}$, and a very small amount of hydroxylated $\mathrm{Cr}$ sites (seen as a broad shoulder at ca. 2167 $\mathrm{cm}^{-1}$ ) was probed. Again, a small feature (inset in Figure 2d) appeared at lower wavenumbers $\left(2090 \mathrm{~cm}^{-1}\right)$ together with another feature at $2062 \mathrm{~cm}^{-1}$ after dosing $\mathrm{CO}$, indicating $\mathrm{Cr}^{2 / 3+}(\mathrm{CO})_{x}$ species. It is important to remark that, in this case, two types of $\mathrm{Cr}$ carbonyl sites are formed, indicating that not one but multiple reduced $\mathrm{Cr}$ sites appear. When the material was degassed at $623 \mathrm{~K}$, a trend similar to that for MIL$100(\mathrm{Cr})$ was seen, meaning more (and more acidic) Lewis acid sites and hydroxylated $\mathrm{Cr}^{3+}$ sites are present. The small spectral feature at $2090 \mathrm{~cm}^{-1}$ remained unchanged, while that at 2062 $\mathrm{cm}^{-1}$ became less intense and was shifted to $2057 \mathrm{~cm}^{-1}$, indicating that the thermal treatment results in a higher degree of reduction (i.e., a red shift indicates an enhanced $\pi$ backdonation of the $\mathrm{Cr}$ sites $).{ }^{53}$

Addition of DEA to MIL-101(Cr) has a dramatic effect on the spectral features (Figure 2f). The band corresponding to 

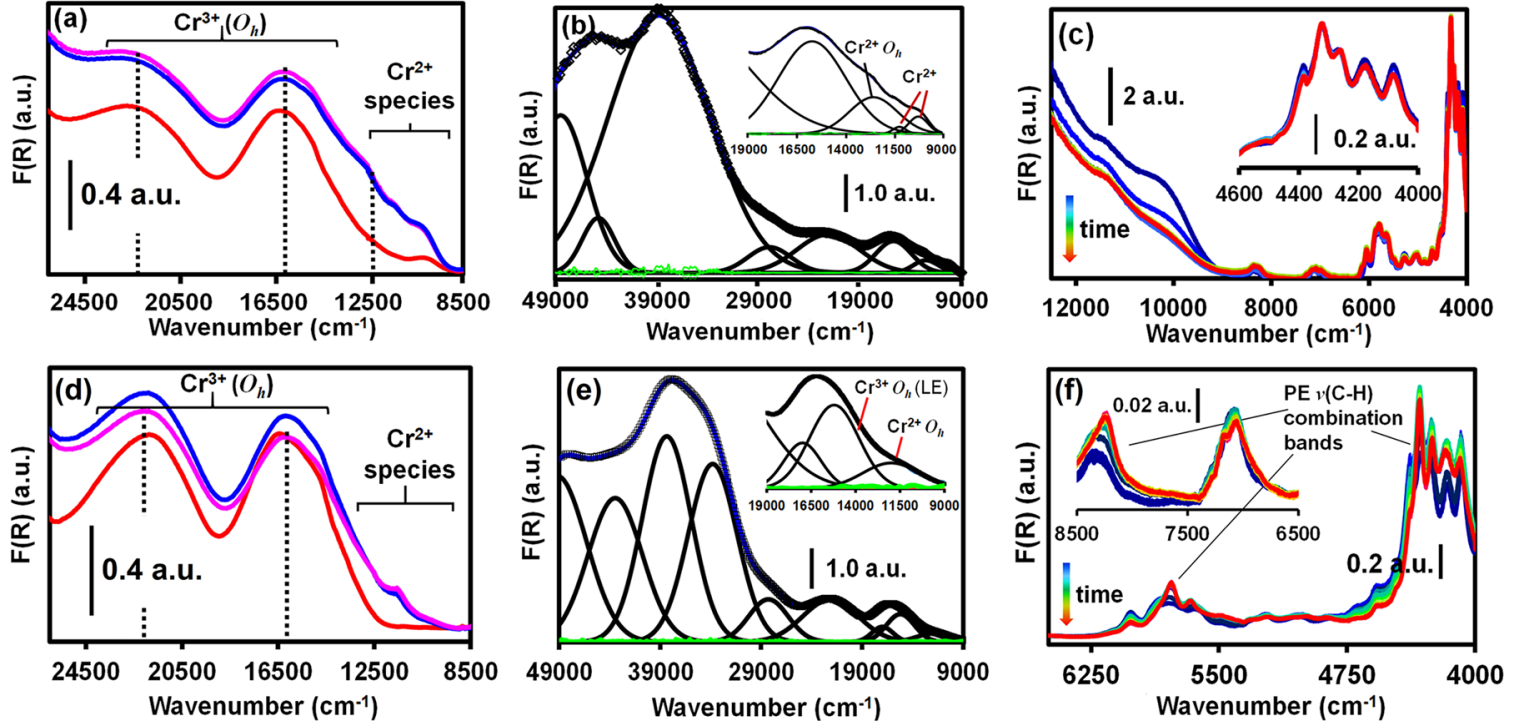

Figure 3. (a) Diffuse reflectance (DRS) spectra in the vis-NIR region for degassed MIL-100(Cr) (red), after injection of 125 equiv of diethylaluminum chloride (DEA) (blue) and after $15 \mathrm{~min}$ (pink). (b) Deconvolution of the UV-vis-NIR DRS spectrum after injection of DEA showing different $\mathrm{Cr}$ species. The inset in (b) shows the presence of small amounts of $\mathrm{Cr}^{2+}$ species (both $\mathrm{O}_{h}$ and $T_{h}$ geometries). Green lines show the residual values of the fitting procedure. (c) DRS spectra in the UV-vis-NIR region after flowing ethylene $\left(10 \mathrm{~mL} \mathrm{~min}^{-1}\right)$ at $298 \mathrm{~K}$ and $1 \mathrm{bar}$ for $1 \mathrm{~h}$ into the cell (from dark blue $(t=0)$ to red $(t=60 \mathrm{~min})$ ). The inset shows bands where polyethylene $\mathrm{C}-\mathrm{H}$ combination bands should appear if polymerization occurred. (d) DRS spectra in the vis-NIR range of activated MIL-101(Cr) (red), after injection of 125 equiv of DEA (blue) and after $15 \mathrm{~min}$ (pink). (e) Deconvolution of the spectrum after injection of DEA showing the different Cr species. The inset in (e) shows the presence of small amounts of $\mathrm{Cr}^{2+}$ species (only $O_{h}$ geometry). Green lines show the residual of the fitting procedure. (f) DRS spectra in the NIR region after flowing ethylene $\left(10 \mathrm{~mL} \mathrm{~min}^{-1}\right)$ at $298 \mathrm{~K}$ and $1 \mathrm{bar}$ for $1 \mathrm{~h}$ into the cell (from dark blue $(t=0)$ to red $(t=60 \mathrm{~min})$ ), showing the bands of crystalline PE forming over time. The inset shows additional combination bands of the polymer $\mathrm{CH}_{2}$ groups, indicating polymer formation in contrast to the case of $(\mathrm{c})$.

Lewis $\mathrm{Cr}^{3+}$ sites broadens significantly, indicating the presence of a wide variety of different highly acidic $\mathrm{Cr}^{3+}$ sites (e.g., extraframework cations, embedded in the lattice), as they are quickly saturated at low $\mathrm{CO}$ pressures. Similarly, the feature at $2065 \mathrm{~cm}^{-1}$, corresponding to the $\mathrm{Cr}^{2+}(\mathrm{CO})_{x}$ species, broadens and increases in intensity dramatically. Again, a large number of differently coordinated $\mathrm{Cr}^{2+}$ sites are formed upon reaction with the alkylating cocatalyst. It is unclear whether any of the carbonyl adducts are binding atop or bridging at this moment. Decomposition of the MIL-101(Cr) framework by DEA results in another unassigned strong spectroscopic feature at $2261 \mathrm{~cm}^{-1}$. Our interpretation of the $\mathrm{Cr}$ reduction is further supported by the in situ UV-vis-NIR DR spectra recorded after addition of DEA (Figure 3).

The bands observed in the spectrum of activated MIL$100(\mathrm{Cr})$ (red spectrum, Figure 3a) correspond to characteristic bands for octahedral $\left(\mathrm{O}_{h}\right) \mathrm{Cr}^{3+}$ species with an oxide-like ligand environment at 24000 and $16000 \mathrm{~cm}^{-1}$ of the $\mathrm{Cr}$ trimers. ${ }^{54,55}$ The $\mathrm{t}_{2 \mathrm{~g}} \rightarrow \mathrm{t}_{2 \mathrm{~g}} \mathrm{e}_{\mathrm{g}}{ }^{1}$ transition, split into the ${ }^{4} \mathrm{~T}_{1 \mathrm{~g}} \leftarrow$ $\mathrm{A}_{2 \mathrm{~g}}$ and the ${ }^{4} \mathrm{~T}_{2 \mathrm{~g}} \leftarrow{ }^{4} \mathrm{~A}_{2 \mathrm{~g}}$ transitions, relate to the higher and lower energy bands, respectively. After addition of DEA (Figure 3a, blue spectrum), the DRS spectrum (Figure 3b) is characterized by two absorption bands at $\sim 11000-10000$ $\mathrm{cm}^{-1}$, indicative of the presence of coordinatively unsaturated $\mathrm{Cr}^{2+}$ species, suggesting the formation of a few reduced chromium sites. This observation is in line with our previous CO-probe FT-IR spectroscopy results and previously mentioned literature. ${ }^{42}$ Other relevant studies show that metal terephthalate MOFs containing exclusively $\mathrm{Cr}^{3+}$ show no absorption below $13000 \mathrm{~cm}^{-1}$ (even for $\mathrm{Cr}_{T_{h}}$ geometries), supported by both time-dependent density functional theory (TD-DFT) calculations and UV-vis experiments, suggesting that indeed the DEA acts as a reducing agent of $\mathrm{Cr}$ cations. ${ }^{56}$ The presence of some $\left[\mathrm{Cr}^{3+} \ldots \mathrm{OH}_{2}\right]$ species even after thermal treatment is verified by the absorption band at $\sim 5220 \mathrm{~cm}^{-1}$ (see Figure S12b), which corresponds to the $\mathrm{O}-\mathrm{H}$ combination band $v_{\mathrm{OH}}+\delta_{\mathrm{OH}}$, confirming the presence of a few remaining nondehydroxylated $\mathrm{Cr}$ sites (as previously shown with FT-IR spectroscopy). ${ }^{47}$ Moreover, we observed a decrease in the intensity of the ligand to metal charge transfer (LMCT) bands of $\pi^{*} \rightarrow \mathrm{d}$ transitions at $45000-38000 \mathrm{~cm}^{-1}$ (Figure S12a). This can be ascribed to a partial degradation of the MOF framework caused by a cleavage of the $\mathrm{Cr}-\mathrm{O}$ bonds, which react with the organo-aluminum species. Flowing ethylene over the activated MOF results in a decrease in the intensity of the characteristic $\mathrm{Cr}^{2+}$ absorption bands (located at ca. $12000-10000 \mathrm{~cm}^{-1}$ ) shortly after, although no significant changes are seen in the $\mathrm{C}-\mathrm{H}$ region, indicating no polyethylene formation. Again, different species were observed for MIL-101(Cr) after both addition of the cocatalyst and addition of ethylene. A much more pronounced decrease in the intensities of the LMCT bands occurred (Figure S13a), corroborating the structural collapse observed in XRD patterns. Deconvolution of the DRS spectrum, as shown in Figure 3e, indicates the presence of reduced $\mathrm{Cr}^{2+}$ sites, although only octahedral species are formed in this case. Furthermore, the main contribution of the low-energy $\mathrm{Cr}^{3+}{ }_{O_{h}}$ is shifted toward ca. $15000 \mathrm{~cm}^{-1}$, indicating changes in the nature of the $\mathrm{Cr}^{3+}$ sites as well, in agreement with the broad band observed in the related FT-IR data. The peaks at 4180, 4250, and $4325 \mathrm{~cm}^{-1}$, which correspond to $\mathrm{C}-\mathrm{H}$ combination bands, indicate alkylation of the MOF. When ethylene was introduced in the cell, the formation of HDPE was steadily 
Table 1. Catalytic Activity of the Different Materials under Study, Including the Physicochemical Properties of the HighDensity Polyethylene Products Obtained after Performing the Ethylene Polymerization Experiments

\begin{tabular}{|c|c|c|c|c|c|c|c|}
\hline catalyst & $\mathrm{Al}: \mathrm{Cr}^{b}$ & activity $^{c}$ & $T_{\mathrm{m}}(\mathrm{K})$ & $\Delta H_{\mathrm{m}}(\mathrm{J} / \mathrm{g})$ & $\% X^{d}$ & $M_{\mathrm{w}}\left(10^{3} \mathrm{kDa}\right)$ & $\mathrm{PDI}^{e}$ \\
\hline \multirow[t]{3}{*}{$1^{a}$} & 100 & 13.0 & 408.3 & 182.1 & 62.2 & 1.8 & 8.3 \\
\hline & 500 & 6.15 & 407.7 & 169.1 & 57.7 & 1.5 & 10.6 \\
\hline & 1000 & 4.12 & 408.2 & 181.9 & 62.1 & 1.2 & 15.7 \\
\hline \multirow[t]{3}{*}{ MIL-100(Cr $)^{a_{1} f}$} & 100 & $1.3 \times 10^{-3}$ & $<0.03$ & & & & \\
\hline & 500 & $0.4 \times 10^{-3}$ & $<0.03$ & & & & \\
\hline & 1000 & $2.1 \times 10^{-3}$ & $<0.03$ & & & & \\
\hline \multirow{2}{*}{$\operatorname{MIL}-101(\mathrm{Cr})^{a}$} & 500 & 4.71 & 410 & 193.1 & 65.9 & 0.9 & 22.6 \\
\hline & 1000 & 5.41 & 410.6 & 182.9 & 62.4 & 0.85 & 18.0 \\
\hline MIL-101(Cr) $)^{a, g}$ & 500 & 0.63 & 409.3 & 187.6 & 64.0 & 1.4 & 11.2 \\
\hline
\end{tabular}

${ }^{a}$ Reaction conditions unless specified otherwise: $1 \mathrm{~h}$ at 10 bar of $\mathrm{C}_{2} \mathrm{H}_{4}$ in $20 \mathrm{~mL}$ of toluene at $298 \mathrm{~K}$ in a $35 \mathrm{~mL}$ Parr-autoclave reactor. ${ }^{b} \mathrm{Al}$ :Cr molar ratio. ${ }^{c}$ Activity: $\mathrm{kg} \mathrm{PE}(\mathrm{mol} \mathrm{Cr})^{-1} \mathrm{~h}^{-1} \mathrm{bar}^{-1}$. ${ }^{d}$ In comparison to $293 \mathrm{~J} / \mathrm{g}$ for $100 \%$ crystalline UHMWPE. ${ }^{e}$ Determined by GPC calibrated with PE and PP standards. ${ }^{f}$ Not enough polymer product for analysis. Experiments at 10, 20, 30, and 40 bar showed no activity. ${ }^{g} \mathrm{MOF} / \mathrm{AlEt}{ }_{2} \mathrm{Cl}$ was stirred together in toluene for $30 \mathrm{~min}$ and filtered into reactor before reaction.

detected by the sharpening of the $\mathrm{C}-\mathrm{H}$ combination bands (Figure 3e).

An increase in the bands at ca. 8400, 5900, and 4500-4000 $\mathrm{cm}^{-1}$ with increasing time corroborates the formation of a solid phase. Indeed, flowing ethylene at slightly higher temperature $(313 \mathrm{~K})$ for $1 \mathrm{~h}$ into the cell, after activation with 100 equiv of DEA, resulted in the formation of significant amounts of HDPE from the gas phase, as confirmed by XRD (Figure S11). In brief, the DRS data show that, in spite of having the same structural motifs (i.e. carboxylates and $\mathrm{Cr}_{3}(\mu$-O) trimers), each MOF forms different $\mathrm{Cr}^{3+}$ and $\mathrm{Cr}^{2+}$ species with similar coordination environments after addition of DEA, and only MIL-101(Cr) is capable of producing some polymer.

In order to compare both MOFs as active catalyst materials, the catalytic polymerization of ethylene in a liquid-phase reactor (in toluene) at 10 bar was carried out. Three different amounts of cocatalyst (i.e., $\mathrm{Al}: \mathrm{Cr}=100,500,1000$ ) were tested, in order to understand the influence of the cocatalyst on the activity and final materials produced. As we hypothesized, Table 1 shows that, despite both MOFs possessing identical topology, MIL-100(Cr) is practically unable to catalyze the formation of polyethylene, regardless of the $\mathrm{Al}: \mathrm{Cr}$ ratio used. In contrast, MIL-101(Cr) showed high activity (i.e., $15.4 \mathrm{~kg}$ $\left.\mathrm{PE}(\mathrm{mol} \mathrm{Cr})^{-1} \mathrm{~h}^{-1} \mathrm{bar}^{-1}\right)$ for a $\mathrm{Al}: \mathrm{Cr}$ ratio of 100 . Higher amounts of cocatalyst were detrimental for the performance under the same reaction conditions (i.e., 4-5 kg PE (mol $\mathrm{Cr})^{-1} \mathrm{~h}^{-1} \mathrm{bar}^{-1}$ ), as previously reported for organoaluminum alkylated Phillips systems. ${ }^{57}$ In order to further understand if pore confinement and anchoring of the $\mathrm{Cr}$ trimer sites have an influence on the active sites, the coordination complex 1 (see Section S1 for details on the synthesis) was used as a homogeneous counterpart. A parallel trend can be observed in activity (Table 1), indicating that the active sites present after addition of DEA are rather similar to those of MIL-101(Cr). The physical properties (melting temperature, $T_{m}$; heat of fusion, $\Delta H_{\mathrm{m}}$ ) of crystalline HDPE are governed by its molecular structure, which is very much determined by the catalytic sites. DSC analyses (Table 1 and Section S8 and Figure S14) were carried out to compare the properties of the obtained materials. As can be concluded from Table 1, both MIL-101(Cr) and complex 1 show the typical $\% X, T_{m}$ and $\Delta H_{\mathrm{m}}$ ranges for HDPE with low branching. To elucidate if the cocatalyst led to Cr leaching of MIL-101, the activity of the solution obtained after mixing DEA with MIL-101(Cr) catalyst was evaluated, showing that indeed some HDPE was formed, with properties similar to those of complex 1. This indicates the same active sites for both catalyst materials: i.e., trimers dissolved in toluene. However, to our surprise, MIL-100(Cr) was inactive under the same conditions.

Accordingly, GPC analysis (Table 1 and Section S9) shows that $M_{\mathrm{w}} \approx(0.85-1.8) \times 10^{3} \mathrm{kDa}$ for the polymers produced, i.e. lower-end to mid-sized HDPE chains, in line with the DSC data. Nevertheless, average molecular weights $\left(M_{\mathrm{w}}\right)$ were slightly higher when nonporous complex 1 was used instead of the zeotypic MIL-101(Cr), following the activity trend. Different correlations between catalyst porosity and $M_{\mathrm{w}}$ have been observed in the past. ${ }^{58,59} \mathrm{We}$ envision a process in which $\mathrm{Cr}$ trimers that leach and remain entrapped in the pores lead to different (probably shorter) polymer chains. This is not the case when complex $\mathbf{1}$ is used: chains can grow with no physical constraints, only limited by chain transfer reactions or catalyst deactivation processes. In our case, the high-MW shoulder is more prominent for low $\mathrm{Al}$ loading and complex 1 catalyst. GPC of the HDPE obtained with complex 1 shows longer tails $\left(\log M_{\mathrm{w}} \approx 6.5\right.$ in Figures S15-S17), which may be associated with enhanced chain transfer reactions, as demonstrated by similar trends with increasing cocatalyst amounts (Section S9 in the Supporting Information) in the experiments in which MIL-101(Cr) was used. Thus, we hypothesize that the variety of chain lengths is related not only to different active sites, MOF-embodiment, or solubilization but also to the presence of increasing cocatalyst amounts. A very high $\mathrm{Al}: \mathrm{Cr}$ may result in an overalkylation, chain termination promotion, or simply alumina coverage of the growing chains. Again, molecular weight distributions (MWDs) and polydispersity index (PDI) values of the polymer obtained after filtration of the MIL$101(\mathrm{Cr})$ fully correlate to that of the material obtained with $\mathbf{1}$. This indicates that the active sites consist of alkylated $\mathrm{Cr}$ sites derived from the trimers in solution. Recent studies have shown multiple possibilities (e.g. metallacycle, Green-Rooney, Cossee-Arman) for the initiation mechanism of ethylene insertion in similar Cr systems. ${ }^{60,61}$ However, the agreement is that chain growth in Cr-based Phillips catalysts operates mostly via the Cossee-Arlman mechanism. ${ }^{2,62}$ In the case of MIL$100(\mathrm{Cr})$ Liu et al. described a mechanism involving multiple metal centers acting via a metallacycle mechanism, yielding short $\left(\mathrm{C}_{6}-\mathrm{C}_{12}\right) \alpha$-olefins. ${ }^{42}$ With the results previously described in this work, we propose that the active species for 
Scheme 1. Tentative Activation of Cr Sites by Diethylaluminum Chloride (DEA) and Subsequent Ethylene Insertion and Polymerization in MIL-101(Cr) Materials

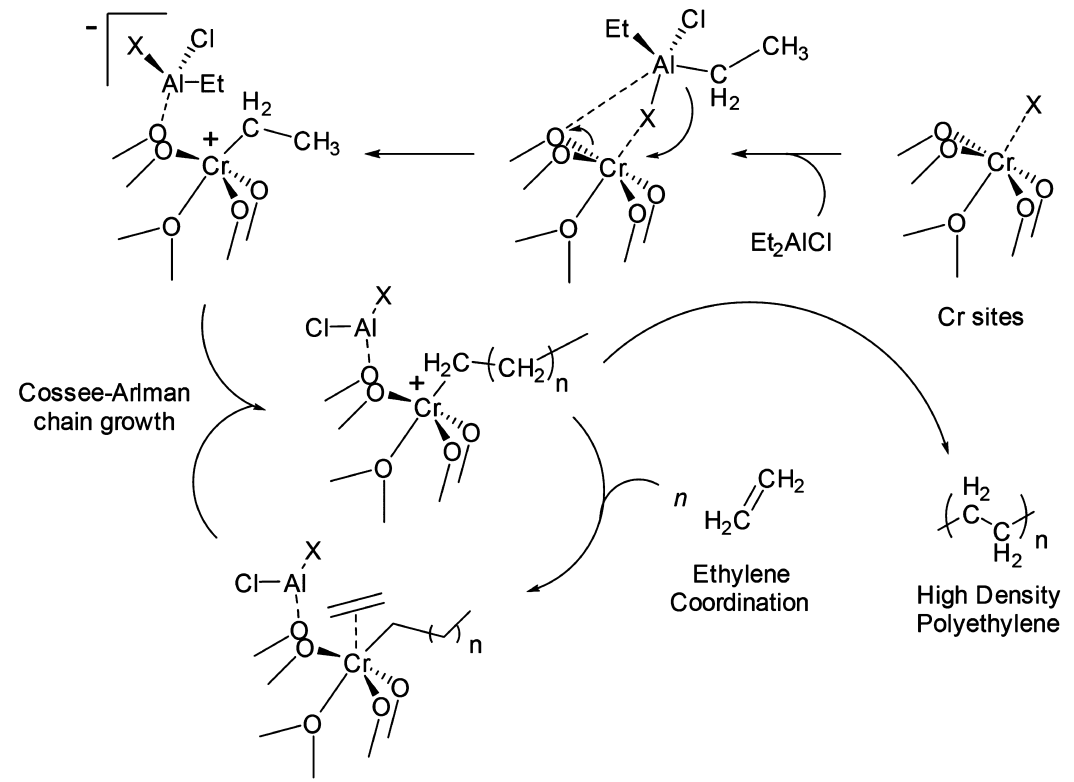

MIL-101(Cr) and 1 consist of Cr-alkyl sites formed by partial degradation of the lattice that lead to the formation of active sites that can insert ethylene, as described in Scheme 1. These $\mathrm{Cr}$ sites arise from the $\mathrm{Cr}$ trimers being most likely $\mathrm{Cr}^{3+}$ or $\mathrm{Cr}^{2+}$ sites (according to the spectroscopy study), although the oxidation state and coordination geometry still remain elusive. The inability of MIL-100(Cr) to fracture would explain the high activity in the formation of $\alpha$-olefins.

3.2. Polymer Morphology. Control over the particle morphology is crucial for large-scale synthesis of polyethylene. ${ }^{1,2,24,25}$ Regardless of the catalytic process employed, a number of issues such as reactor fouling, heat transfer, and product properties have to be taken into account. As already mentioned, Cr-based catalysts are typically supported onto solid oxides that crumble during ethylene polymerization, allowing the necessary chain growth. The above results led us to evaluate the ability of both MIL-100(Cr) and MIL-101(Cr) to generate structured polyethylene upon fragmentation of the MOF catalysts. Surprisingly, Figure $4 \mathrm{a}, \mathrm{b}$ shows that, under identical reaction conditions, MIL-101(Cr) generates spherical beads of polyethylene, in contrast to MIL-100(Cr) (Figure $4 \mathrm{c}, \mathrm{d})$, which produces nanosized $(<1 \mu \mathrm{m})$, ill-shaped material. These findings show that not only is MIL-101(Cr) active in ethylene polymerization but also that its use as a catalyst confers to the polymer a certain architecture at the macroscale. Experiments with different $\mathrm{Al}: \mathrm{Cr}$ ratios show that the templating effect is retained in every case, with a minimal effect on the size distribution (Figure S17). Analogously, a similarly poorly shaped material was covering MIL-100(Cr) crystallites for all the $\mathrm{Al}: \mathrm{Cr}$ ratios tested, indicating no significant chain growth under these conditions.

We explain this difference on the basis of our previous XRD analysis, which indicated the total collapse of MIL-101(Cr). This enables the $\mathrm{Cr}$ active sites to grow polymer chains in the solvent medium, in contrast to MIL-100(Cr), which retains its crystalline structure, preventing the crystallites from fracturing upon ethylene insertion. Thus, the obtained SEM images indicate that MIL-101(Cr) acts as a sacrificial template, in which the catalytically active species reside and that is later covered on polyethylene during the reaction, leading to the observed polymer beads.

The SEM images of the polymer obtained with catalytic complex 1 show randomly oriented, intergrown polymer fibers of ca. 3-5 $\mu \mathrm{m}$ thickness (for the same $\mathrm{Al}$ :Cr ratios; Figure S17), indicating that, in addition to the $\mathrm{Cr}$ trimer units, a solid scaffold is required to control the chain growth. In order to confirm its role as a structural template and discriminate it from possible leached species that polymerize in solution, the SEM images of the polymer recovered from toluene filtered after suspending DEA-activated MIL-101(Cr) were recorded. Figure $4 \mathrm{~g}$,h shows fibers very similar to those obtained with complex 1, proving that the sole presence of $\mathrm{Cr}$ trimers in solution is not enough to obtain the morphologically controlled polymer. SEM images in Figure 5 and Figure S19 of the recovered MIL- $100(\mathrm{Cr})$ solid after reaction with 500 equiv of cocatalyst corroborate our hypothesis. After filtration from the toluene solvent, most of the MOF crystallites appeared intact (compare to SEM in Figure S9), and only a few polymer fibers arising from the pores were observed. Some species that have leached into solution (the strong alkylating agent causes partial degradation of MIL-100, as shown by XRD) formed polyethylene layers that covered the MOF (Figure S19). This has been previously observed in other catalysts supported in porous polymers. ${ }^{59}$

Although $\mathrm{Cr}-\mathrm{O}$ bond strength has been argued as a possible reason for differences in reactivity (as it may not allow for the alkylation of $\mathrm{Cr}$ ), X-ray diffraction studies have shown that $\mathrm{Cr}-\mathrm{O}$ distances are ca. $1.975 \AA$ for all catalysts, indicating very similar bonding strengths. On the other hand, porosity has been shown to greatly affect activity for ethylene polymerization in Cr-based systems. Differences in activity are due to the porosity of each material. It is well-known that support and catalyst porosity have a tremendous effect on polymer production. $^{2}$

It is generally accepted that at least $V_{\mathrm{p}} \geq 1.0 \mathrm{~cm}^{3} \mathrm{~g}^{-1}$ is necessary in silica in order for the support to crumble upon chain growth. Despite the different chemical and physical nature in comparison to silica and its high porosity, MIL-100 

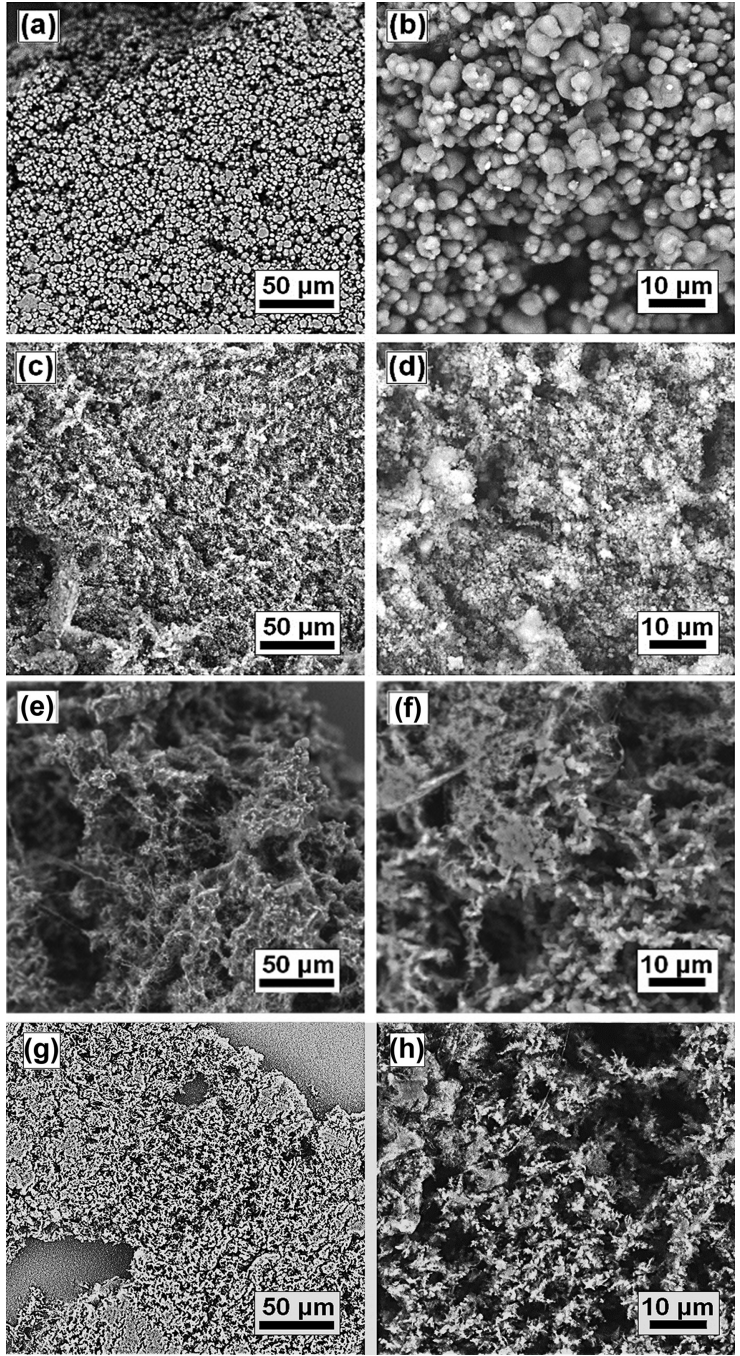

Figure 4. Scanning electron microscopy (SEM) micrographs of the polymer product obtained with (a, b) MIL-101(Cr), (c, d) MIL$100(\mathrm{Cr})$ (note that only nanosized crystallites are observed at this magnification), complex 1 (e, f), and the leached Cr from MIL$101(\mathrm{Cr})(\mathrm{g}, \mathrm{h})$. Conditions: $\mathrm{Al}: \mathrm{Cr}$ mol ratio of 100 , diethylaluminum chloride (DEA), $T=298 \mathrm{~K}, p=10$ bar of $\mathrm{C}_{2} \mathrm{H}_{4}, t=1 \mathrm{~h}$.

showed a pore volume $\left(V_{\mathrm{p}}=0.81 \mathrm{~cm}^{3} \mathrm{~g}^{-1}\right)$ below that threshold (Figure S3). In contrast, MIL-101 ( $V_{\mathrm{p}}=1.27 \mathrm{~cm}^{3}$ $\mathrm{g}^{-1}$ ) was well above the threshold (Figure S4), pointing to a critical effect on polymerization activity. As pointed out by McDaniel, it is not the difference in pore volume but the fragility (which may arise from this difference in pore volume and seems to be the cause for this difference) that prevents higher polymerization activity. In fact, not only a difference in pore volume but also a difference in pore diameter and window exists. While MIL-100 has two types of cages, of 25 and $29 \AA$ diameter (with pore windows 5 and $8.6 \AA$, respectively), ${ }^{43}$ MIL-101 exhibits diameters of 27 and $34 \AA$ (with 11.6 and 16 $\AA$ windows $).{ }^{44}$ This difference in pore diameter, specifically the presence of the larger $34 \AA$ cages, seems to be critical for ethylene polymerization. We argue that chain growth occurring in that specific cage is enough to tear apart MIL-101 crystallites during the process, giving rise to new active sites that further polymerize ethylene. DFT pore size distributions shown in Figure 6 clearly illustrate the difference in pore diameter cages between both MOFs.

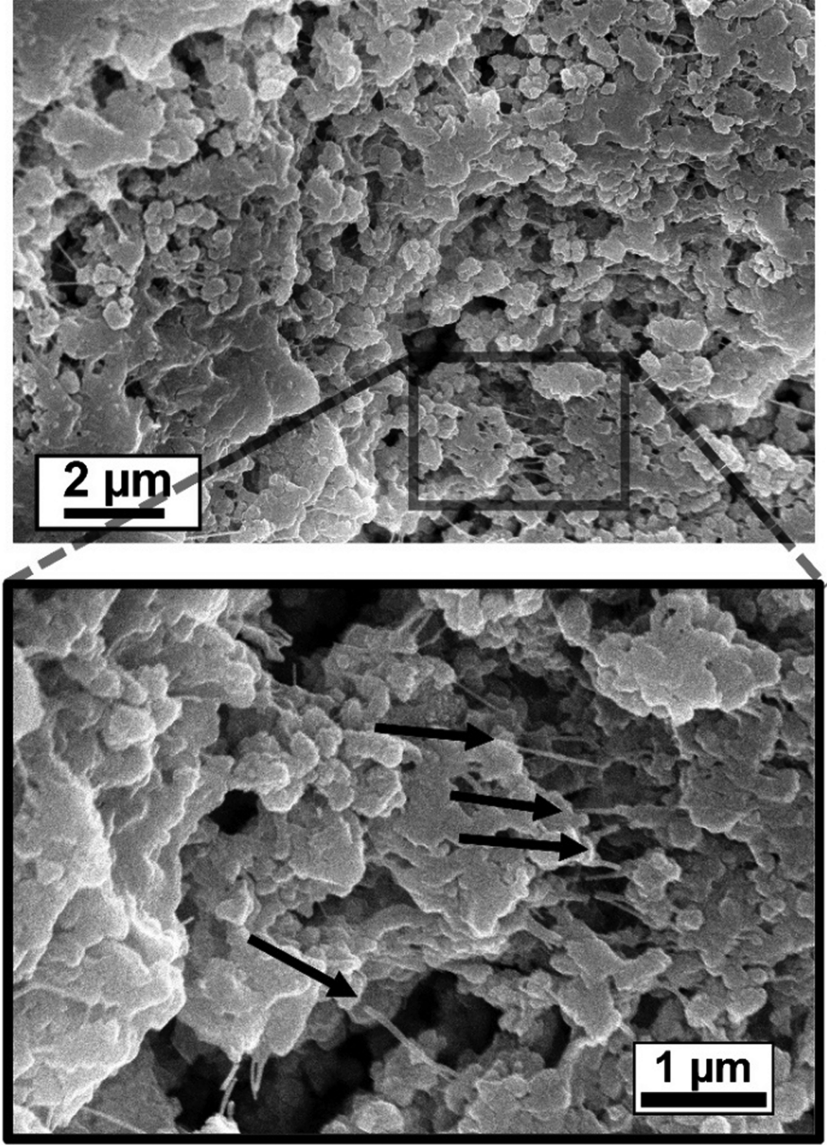

Figure 5. Scanning electron microscopy (SEM) micrographs of MIL$100(\mathrm{Cr})$ after reaction $\left(10\right.$ bar of $\mathrm{C}_{2} \mathrm{H}_{4}, 298 \mathrm{~K}, 500$ equiv of DEA, toluene, $1 \mathrm{~h}$ ) at high magnification, showing MIL-100(Cr) crystallites still intact. The arrows in the inset image indicate polymer fibers of MOF crystallites that were not able to fracture. However, no evident signs of polymerization around the MOF crystallites, into shaped beads as is the case for MIL-101(Cr), were observed. In Figure 5, the inset shows a few polymer fibers that emerge from certain MOF crystallites. This is in stark contrast with MIL-101(Cr) and complex 1, and it evidences the inability of MIL-100(Cr) to crumble upon ethylene insertion.

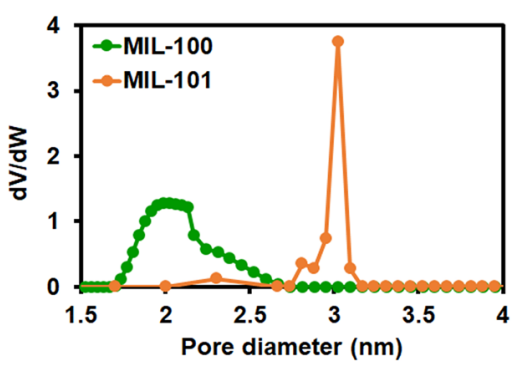

Figure 6. Density functional theory (DFT) pore size distributions of both MOFs calculated from the experimental $\mathrm{N}_{2}$ adsorption isotherms at $77 \mathrm{~K}$.

An alternative explanation for these differences in reactivity may be the low temperature, i.e. $298 \mathrm{~K}$, at which the polymerization was conducted, which would be insufficient to collapse the MIL-100(Cr) framework.

For coordination complex 1 , it readily dissolves in the reaction medium (toluene), acting as a homogeneous catalyst 
(a)

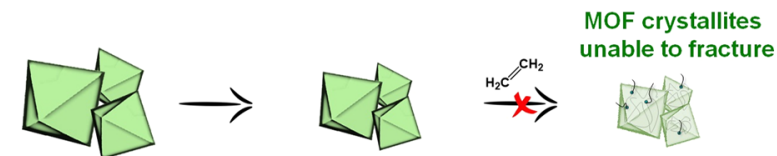

(b)

$$
\mathrm{MIL}-100+\mathrm{Et}_{2} \mathrm{AICI}
$$
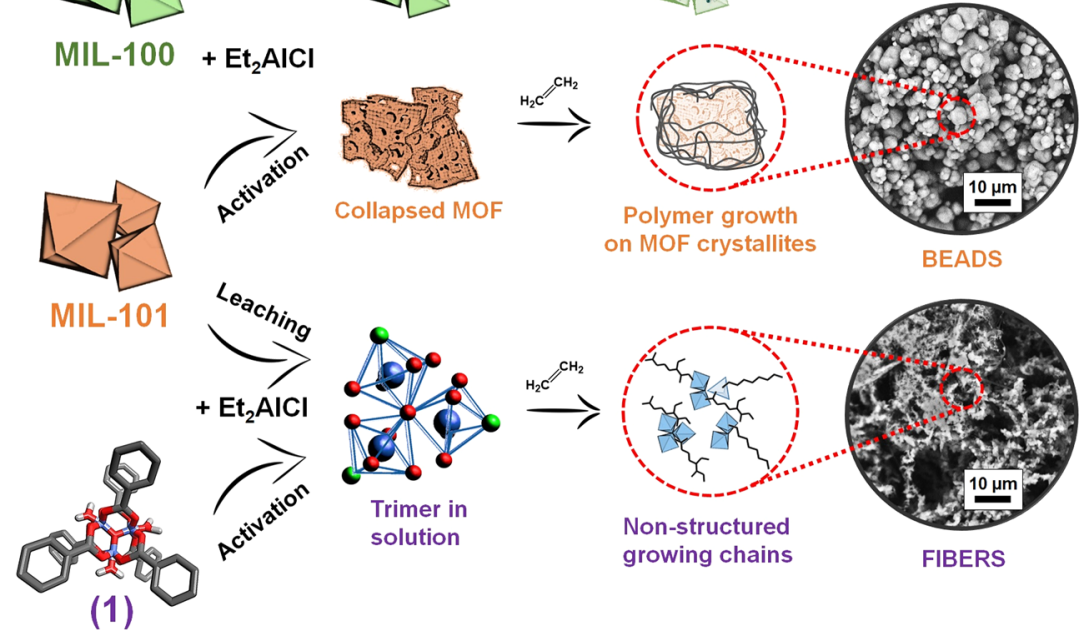

Figure 7. (a) MIL-100(Cr) is unable to fracture upon polyethylene formation, resulting in low catalytic activity. (b) MIL-101(Cr) is degraded and partially leaches $\mathrm{Cr}$ clusters into the solution upon addition of the cocatalyst, leading to different morphologies. (c) Coordination complex 1 in solution generates polymer fibers, as the chain growth is not templated by any solid support.

with no need of fracturing, as observed in the SEM imaged randomly oriented polymer fibers.

In Figure 7, a summary of the different activities and morphologies that are obtained in ethylene polymerization under the studied conditions is presented. MIL-101(Cr) is a competent catalyst that, although it performs below commercial Philips benchmarks, is able to structure the polymer at the microscale, while producing high-molecularweight PE with relatively narrow PDI (orange). In contrast, MIL-100(Cr) (green) is unable to fracture and produce polymer, while complex 1 results in a nonstructured polymer (purple).

\section{CONCLUSIONS}

It was found that the MOF material MIL-101(Cr) can be used as an active morphology template in the catalytic polymerization of ethylene. In contrast, the isoreticular MIL-100(Cr) material is unable to reach significant ethylene polymerization activities due to the high stability of the crystallites against fragmentation. XRD studies revealed that, while MIL-100(Cr) is still crystalline after addition of the organo-aluminum cocatalyst (i.e., diethylaluminum chloride, DEA), MIL$101(\mathrm{Cr})$ completely collapses, leading to an amorphous solid material. Furthermore, in situ FT-IR spectroscopy with $\mathrm{CO}$ as a probe molecule and UV-vis-NIR DRS spectroscopy show that different reduced and alkylated $\mathrm{Cr}$ sites are formed for each MOF, further indicating different stabilities toward the cocatalyst DEA. The exact nature of the active $\mathrm{Cr}$ species (as in the case of the long-debated Phillips system) is not yet fully understood, but experiments with the putative homogeneous coordination complex showed trends in reactivity in the production of HDPE similar to those of MIL-101(Cr), suggesting that alkylated $\mathrm{Cr}$ sites are the main ethylene polymerization sites. In contrast, MIL-100(Cr) shows very low polymerization activity, mostly producing gaseous and liquid olefins instead.

SEM studies revealed that, in addition to catalyzing chain growth, MIL-101 $(\mathrm{Cr})$ can also act as a structure modulator for the polymer material obtained, leading to the formation of spherical micrometer-sized polyethylene beads. Again, control experiments with the homogeneous complex 1 confirm this hypothesis, as the coordination complex catalyst 1 produces interwoven polymer fibers in a random orientation. In other words, Cr-based MOF materials have the ability to act as a selfsacrificial template for structuring polymer materials while they form in the internal pore structure over active ethylene polymerization sites. We foresee that our research will foster the design of new polyolefin architectures, as well as expand our understanding of highly stable MOFs (i.e. MIL-100 and 101) upon reaction with reactive activators for the selective production of short-chain olefins, such as 1-octene and 1hexene.

\section{ASSOCIATED CONTENT}

\section{Supporting Information}

The Supporting Information is available free of charge on the ACS Publications website at DOI: 10.1021/acscatal.9b00150.

Data and experimental details for the synthesis and characterization of coordination complex $\mathbf{1}$, experimental details on XRD, $\mathrm{N}_{2}$ adsorption at $77 \mathrm{~K}$, TGA-MS, and SEM of the MIL-100 and MIL-101 materials, characterization of polyethylene obtained from the gas phase by XRD with MIL-101(Cr), more detailed UVvis-NIR DRS experiments upon addition of DEA, and details on the physicochemical properties of the polymer materials obtained by DSC, GPC, and additional SEM images (PDF)

\section{AUTHOR INFORMATION}

\section{Corresponding Author}

*E-mail for B.M.W.: b.m.weckhuysen@uu.nl.

\section{ORCID}

Bert M. Weckhuysen: 0000-0001-5245-1426 


\section{Author Contributions}

${ }^{\dagger}$ M.R.-T. and P.D.P. contributed equally with the experiments and preparation of the manuscript. M.R.-T., P.D.P., and M.K.J. carried out experiments and contributed to the writing of the manuscript. B.M.W. supervised the research and contributed to the writing of the manuscript.

\section{Notes}

The authors declare no competing financial interest.

\section{ACKNOWLEDGMENTS}

T. N. Ran (Utrecht University, UU) is thanked for the ESI-MS measurements, while C. Hernández-Mejia (Utrecht University, UU) is acknowledged for help during the in situ FT-IR spectroscopy experiments. We also thank N. Friederichs (SABIC) for the GPC measurements. N. Maaskant (UU), R. Pluijm (UU), G. de Reijer (UU), and P. Dolata (UU) are acknowledged for their help with sample preparation. This project has received funding from the European Union Horizon 2020 research and innovation program under the Marie-Sklodowska-Curie grant agreement 641887 (DEFNET) as well as funding from TKI Chemistry (The Netherlands).

\section{REFERENCES}

(1) Soares, J. B. P.; Leonardo, C. S.; In Handbook of Polymer Reaction Engineering, 2nd ed.; Meyer, T.; Keurentjes, J., Eds.; Wiley-VCH: Weinheim, Germany, 2008; pp 366-395.

(2) McDaniel, M. P.; Gates, B. C.; Knözinger, H. A Review of the Phillips Supported Chromium Catalyst and Its Commercial Use for Ethylene Polymerization. Adv. Catal. 2010, 53, 123-606.

(3) Eisch, J. J. Fifty Years of Ziegler-Natta Polymerization: From Serendipity to Science. A Personal Account. Organometallics 2012, 31, 4917-4932.

(4) Hamielec, A. E.; Soares, J. B. P. Polymerization Reaction Engineering - Metallocene Catalysts. Prog. Polym. Sci. 1996, 21, 651-706.

(5) Weckhuysen, B. M.; Rao, R. R.; Pelgrims, J.; Schoonheydt, R. A.; Bodart, P.; Debras, G.; Collart, O.; Van Der Voort, P.; Vansant, E. F. Synthesis, Spectroscopy and Catalysis of [ $\mathrm{Cr}(\mathrm{acac}) 3]$ Complexes Grafted onto MCM 41 Materials: Formation of Polyethylene Nanofibres within Mesoporous Crystalline Aluminosilicates. Chem. Eur. J. 2000, 6, 2960-2970.

(6) Ramachandra Rao, R. M.; Weckhuysen, B. M.; Schoonheydt, R. A. Ethylene Polymerization over Chromium Complexes Grafted onto MCM-41 Materials. Chem. Commun. 1999, 445-446.

(7) Kageyama, K.; Tamazawa, J.-I.; Aida, T. Extrusion Polymerization: Catalyzed Synthesis of Crystalline Linear Polyethylene Nanofibers Within a Mesoporous Silica. Science 1999, 285, 21132115.

(8) Cesano, F.; Groppo, E.; Bonino, F.; Damin, A.; Lamberti, C.; Bordiga, S.; Zecchina, A. Polyethylene Microtubes from Silica Fiber based Polyethylene Composites Synthesized by an InSitu Catalytic Method. Adv. Mater. 2006, 18, 3111-3114.

(9) Lehmus, P.; Rieger, B. Nanoscale Polymerization Reactors for Polymer Fibers. Science 1999, 285, 2081-2082.

(10) Tajima, K.; Aida, T. Controlled Polymerizations with Constrained Geometries. Chem. Commun. 2000, 2399-2412.

(11) Uemura, T.; Kaseda, T.; Sasaki, Y.; Inukai, M.; Toriyama, T.; Takahara, A.; Jinnai, H.; Kitagawa, S. Mixing of Immiscible Polymers using Nanoporous Coordination Templates. Nat. Commun. 2015, 6, 7473.

(12) Uemura, T.; Kitagawa, K.; Horike, S.; Kawamura, T.; Kitagawa, S.; Mizuno, M.; Endo, K. Radical Polymerisation of Styrene in Porous Coordination Polymers. Chem. Commun. 2005, 5968-5970.

(13) Uemura, T.; Hiramatsu, D.; Kubota, Y.; Takata, M.; Kitagawa, S. Topotactic Linear Radical Polymerization of Divinylbenzenes in
Porous Coordination Polymers. Angew. Chem., Int. Ed. 2007, 46, 4987-4990.

(14) Uemura, T.; Ono, Y.; Kitagawa, K.; Kitagawa, S. Radical Polymerization of Vinyl Monomers in Porous Coordination Polymers: Nanochannel Size Effects on Reactivity, Molecular Weight, and Stereostructure. Macromolecules 2008, 41, 87-94.

(15) Wang, S.; Kitao, T.; Guillou, N.; Wahiduzzaman, M.; Martineau-Corcos, C.; Nouar, F.; Tissot, A.; Binet, L.; Ramsahye, N.; Devautour-Vinot, S. A.; Kitagawa, S.; Seki, S.; Tsutsui, Y.; Briois, V.; Steunou, N.; Maurin, G.; Uemura, T.; Serre, C. A phase transformable ultrastable titanium-carboxylate framework for photoconduction. Nat. Commun. 2018, 9, 1660.

(16) Takayanagi, M.; Pakhira, S.; Nagaoka, M. Control of Diffusion and Conformation Behavior of Methyl Methacrylate Monomer by Phenylene Fin in Porous Coordination Polymers. J. Phys. Chem. C 2015, 119, 27291-27292.

(17) Kitao, T.; Zhang, Y.; Kitagawa, S.; Wang, B.; Uemura, T. Hybridization of MOFs and Polymers. Chem. Soc. Rev. 2017, 46, $3108-3133$

(18) Zhou, H.-C.; Long, J. R.; Yaghi, O. M. Introduction to MetalOrganic Frameworks. Chem. Rev. 2012, 112, 673-674.

(19) Corma, A.; García, H.; Llabrés i Xamena, F. X. Engineering Metal Organic Frameworks for Heterogeneous Catalysis. Chem. Rev. 2010, 110, 4606-4655.

(20) Rogge, S. M. J.; Bavykina, A.; Hajek, J.; Garcia, H.; OlivosSuarez, A. I.; Sepulveda-Escribano, A.; Vimont, A.; Clet, G.; Bazin, P.; Kapteijn, F.; Daturi, M.; Ramos-Fernandez, E. V.; Llabres i Xamena, F. X.; Van Speybroeck, V.; Gascon, J. Metal-organic and Covalent Organic Frameworks as Single-site Catalysts. Chem. Soc. Rev. 2017, 46, 3134-3184.

(21) Cohen, S. M.; Zhang, Z.; Boissonnault, J. A. Toward "metalloMOFzymes": Metal-Organic Frameworks with Single-Site Metal Catalysts for Small-Molecule Transformations. Inorg. Chem. 2016, 55, 7281-7290.

(22) Kissin, Y. V. Polyethylene, linear low density (LLDPE). In KirkOthmer Encyclopedia of Chemical Technology, 5th ed.; Wiley: New York, 2006; Vol. 20, pp 179-211.

(23) Lappin, G. R.; Nemec, L. H.; Sauer, J. D.; Wagner, J. D. Higher Olefins. In Kirk-Othmer Encyclopedia of Chemical Technology, 4th ed.; Wiley: New York, 2000; Vol. 17, pp 709-723.

(24) Maraschin, N., Polyethylene, high density (HDPE). In KirkOthmer Encyclopedia of Chemical Technology, 5th ed.; Wiley: New York, 2006; Vol. 20, pp 211-239.

(25) McDaniel, M. P.; DesLauriers, P. J. Ethylene Polymers, HDPE. In Kirk-Othmer Encyclopedia of Chemical Technology; Wiley: New York, 2015; pp 1-40.

(26) Lieberman, R. B.; Dorini, M.; Mei, G.; Rinaldi, R.; Penzo, G.; Berge, G. T. Polypropylene. In Kirk-Othmer Encyclopedia of Chemical Technology, 4th ed.; Wiley: New York, 2000; Vol. 17, pp 1-15.

(27) Canivet, J.; Aguado, S.; Schuurman, Y.; Farrusseng, D. MOFSupported Selective Ethylene Dimerization Single-Site Catalysts through One-Pot Postsynthetic Modification. J. Am. Chem. Soc. 2013, 135, 4195-4198.

(28) Madrahimov, S. T.; Gallagher, J. R.; Zhang, G.; Meinhart, Z.; Garibay, S. J.; Delferro, M.; Miller, J. T.; Farha, O. K.; Hupp, J. T.; Nguyen, S. T. Gas-Phase Dimerization of Ethylene under Mild Conditions Catalyzed by MOF Materials Containing (bpy) $\mathrm{Ni}^{\mathrm{II}}$ Complexes. ACS Catal. 2015, 5, 6713-6718.

(29) Metzger, E. D.; Brozek, C. K.; Comito, R. J.; Dinca, M. Selective Dimerization of Ethylene to 1-Butene with a Porous Catalyst. ACS Cent. Sci. 2016, 2, 148-153.

(30) Metzger, E. D.; Comito, R. J.; Hendon, C. H.; Dinca, M. Mechanism of Single-Site Molecule-Like Catalytic Ethylene Dimerization in Ni-MFU-4l. J. Am. Chem. Soc. 2017, 139, 757-762.

(31) Pellizzeri, S.; Barona, M.; Bernales, V.; Miró, P.; Liao, P.; Gagliardi, L.; Snurr, R. Q.; Getman, R. B. Catalytic Descriptors and Electronic Properties of Single-site Catalysts for Ethene Dimerization to 1-butene. Catal. Today 2018, 312, 149-157. 
(32) Ye, J.; Gagliardi, L.; Cramer, C. J.; Truhlar, D. G. Single Ni Atoms and Ni4 Clusters have Similar Catalytic Activity for Ethylene Dimerization. J. Catal. 2017, 354, 278-286.

(33) Bernales, V.; League, A. B.; Li, Z.; Schweitzer, N. M.; Peters, A. W.; Carlson, R. K.; Hupp, J. T.; Cramer, C. J.; Farha, O. K.; Gagliardi, L. Computationally Guided Discovery of a Catalytic CobaltDecorated Metal-Organic Framework for Ethylene Dimerization. J. Phys. Chem. C 2016, 120, 23576-23583.

(34) Liu, B.; Jie, S.; Bu, Z.; Li, B.-G. A MOF-supported Chromium Catalyst for Ethylene Polymerization through Post-synthetic Modification. J. Mol. Catal. A: Chem. 2014, 387, 63-68.

(35) Ji, P.; Solomon, J. B.; Lin, Z.; Johnson, A.; Jordan, R. F.; Lin, W. Transformation of Metal-Organic Framework Secondary Building Units into Hexanuclear Zr-Alkyl Catalysts for Ethylene Polymerization. J. Am. Chem. Soc. 2017, 139, 11325-11328.

(36) Comito, R. J.; Fritzsching, K. J.; Sundell, B. J.; Schmidt-Rohr, K.; Dinca, M. Single-Site Heterogeneous Catalysts for Olefin Polymerization Enabled by Cation Exchange in a Metal-Organic Framework. J. Am. Chem. Soc. 2016, 138, 10232-10237.

(37) Klet, R. C.; Tussupbayev, S.; Borycz, J.; Gallagher, J. R.; Stalzer, M. M.; Miller, J. T.; Gagliardi, L.; Hupp, J. T.; Marks, T. J.; Cramer, C. J.; Delferro, M.; Farha, O. K. Single-Site Organozirconium Catalyst Embedded in a Metal-Organic Framework. J. Am. Chem. Soc. 2015, $137,15680-15683$

(38) Comito, R. J.; Metzger, E. D.; Wu, Z.; Zhang, G.; Hendon, C. H.; Miller, J. T.; Dinca, M. Selective Dimerization of Propylene with Ni-MFU-4l. Organometallics 2017, 36, 1681-1683.

(39) Mlinar, A. N.; Keitz, B. K.; Gygi, D.; Bloch, E. D.; Long, J. R.; Bell, A. T. Selective Propene Oligomerization with Nickel(II)-Based Metal-Organic Frameworks. ACS Catal. 2014, 4, 717-721.

(40) Dubey, R. J. C.; Comito, R. J.; Wu, Z.; Zhang, G.; Rieth, A. J.; Hendon, C. H.; Miller, J. T.; Dinca, M. Highly Stereoselective Heterogeneous Diene Polymerization by Co-MFU-4l: A Single-Site Catalyst Prepared by Cation Exchange. J. Am. Chem. Soc. 2017, 139, 12664-12669.

(41) Vitorino, M. J.; Devic, T.; Tromp, M.; Férey, G.; Visseaux, M. Lanthanide Metal Organic Frameworks as Ziegler-Natta Catalysts for the Selective Polymerization of Isoprene. Macromol. Chem. Phys. 2009, 210, 1923-1932.

(42) Liu, S.; Zhang, Y.; Han, Y.; Feng, G.; Gao, F.; Wang, H.; Qiu, P. Selective Ethylene Oligomerization with Chromium-Based MetalOrganic Framework MIL-100 Evacuated under Different Temperatures. Organometallics 2017, 36, 632-638.

(43) Férey, G.; Serre, C.; Mellot-Draznieks, C.; Millange, F.; Surblé, S.; Dutour, J.; Margiolaki, I. A Hybrid Solid with Giant Pores Prepared by a Combination of Targeted Chemistry, Simulation, and Powder Diffraction. Angew. Chem., Int. Ed. 2004, 43, 6296-6301.

(44) Férey, G.; Mellot-Draznieks, C.; Serre, C.; Millange, F.; Dutour, J.; Surblé, S.; Margiolaki, I. A Chromium Terephthalate-Based Solid with Unusually Large Pore Volumes and Surface Area. Science 2005, 309, 2040-2042.

(45) Harton, A.; Nagi, M. K.; Glass, M. M.; Junk, P. C.; Atwood, J. L.; Vincent, J. B. Synthesis and Characterization of Symmetric and Unsymmetric Oxo-bridged Trinuclear Chromium Benzoate Complexes: Crystal and Molecular Structure of $\left[\mathrm{Cr}_{3} \mathrm{O}\left(\mathrm{O}_{2} \mathrm{CPh}\right)_{6}(\mathrm{py})_{3}\right]$ $\mathrm{ClO}_{4}$. Inorg. Chim. Acta 1994, 217, 171-179.

(46) Lebedev, O. I.; Millange, F.; Serre, C.; Van Tendeloo, G.; Férey, G. First Direct Imaging of Giant Pores of the Metal-Organic Framework MIL-101. Chem. Mater. 2005, 17, 6525-6527.

(47) Vimont, A.; Goupil, J. M.; Lavalley, J. C.; Daturi, M.; Surblé, S.; Serre, C.; Millange, F.; Férey, G.; Audebrand, N. Investigation of Acid Sites in a Zeotypic Giant Pores Chromium(III) Carboxylate. J. Am. Chem. Soc. 2006, 128, 3218-3227.

(48) Shufler, S. L.; Sternberg, H. W.; Friedel, R. A. Infrared Spectrum and Structure of Chromium Hexacarbonyl, $\mathrm{Cr}(\mathrm{CO})_{6}$. J. Am. Chem. Soc. 1956, 78, 2687-2688.

(49) Groppo, E.; Lamberti, C.; Bordiga, S.; Spoto, G.; Zecchina, A. The Structure of Active Centers and the Ethylene Polymerization
Mechanism on the $\mathrm{Cr} / \mathrm{SiO}_{2}$ Catalyst: A Frontier for the Characterization Methods. Chem. Rev. 2005, 105, 115-154.

(50) Groppo, E.; Lamberti, C.; Cesano, F.; Zecchina, A. On the Fraction of CrII Sites involved in the $\mathrm{C}_{2} \mathrm{H}_{4}$ Polymerization on the $\mathrm{Cr} /$ $\mathrm{SiO}_{2}$ Phillips Catalyst: A Quantification by FTIR Spectroscopy. Phys. Chem. Chem. Phys. 2006, 8, 2453-2456.

(51) Kohler, S. D.; Ekerdt, J. G. Infrared Spectroscopic Characterization of Chromium Carbonyl Species Formed by Ultraviolet Photoreduction of Silica-Supported Chromium(VI) in Carbon Monoxide. J. Phys. Chem. 1994, 98, 4336-4342.

(52) Nenu, C. N.; Groppo, E.; Lamberti, C.; Beale, A. M.; Visser, T.; Zecchina, A.; Weckhuysen, B. M. Dichloromethane as a Selective Modifying Agent To Create a Family of Highly Reactive Chromium Polymerization Sites. Angew. Chem., Int. Ed. 2007, 46, 1465-1468.

(53) Hadjiivanov, K. I.; Vayssilov, G. N. Characterization of oxide surfaces and zeolites by carbon monoxide as an IR probe molecule. Adv. Catal. 2002, 47, 307-511.

(54) Weckhuysen, B. M.; Verberckmoes, A. A.; Baets, A. R. D.; Schoonheydt, R. A. Diffuse Reflectance Spectroscopy of Supported Chromium Oxide Catalysts: A Self-Modeling Mixture Analysis. J. Catal. 1997, 166, 160-171.

(55) Sattler, J. J. H. B.; Gonzalez-Jimenez, I. D.; Mens, A. M.; Arias, M.; Visser, T.; Weckhuysen, B. M. Operando UV-Vis spectroscopy of a catalytic solid in a pilot-scale reactor: deactivation of a $\mathrm{CrO}_{\mathrm{x}} / \mathrm{Al}_{2} \mathrm{O}_{3}$ propane dehydrogenation catalyst. Chem. Commun. 2013, 49, 15181520.

(56) Brozek, C. K.; Dinca, M. $\mathrm{Ti}^{3+}-, \mathrm{V}^{2+/ 3+}-, \mathrm{Cr}^{2+/ 3+}-, \mathrm{Mn}^{2+}$, and $\mathrm{Fe}^{2+}$-Substituted MOF-5 and Redox Reactivity in Cr- and Fe-MOF-5. J. Am. Chem. Soc. 2013, 135, 12886-12891.

(57) Zeng, Y.; Chammingkwan, P.; Baba, R.; Taniike, T.; Terano, M. Activation and Deactivation of Phillips Catalyst for Ethylene Polymerization Using Various Activators. Macromol. React. Eng. 2017, 11, 1600046-1600051.

(58) McDaniel, M. P. Influence of Catalyst Porosity on Ethylene Polymerization. ACS Catal. 2011, 1, 1394-1407.

(59) Wang, X.; Li, Z.; Han, X.; Han, Z.; Bai, Y. Highly tunable porous organic polymer (POP) supports for metallocene-based ethylene polymerization. Appl. Surf. Sci. 2017, 420, 496.

(60) McGuinness, D. S.; Davies, N. W.; Horne, J.; Ivanov, I. Unraveling the Mechanism of Polymerization with the Phillips Catalyst. Organometallics 2010, 29, 6111-6116.

(61) Venderbosch, B.; Oudsen, J. P. H.; Wolzak, L. A.; Martin, D. J.; Korstanje, T. H.; Tromp, M. Spectroscopic investigation of the activation of a chromium-pyrrolyl ethene trimerization catalyst. ACS Catal. 2019, 9, 1197-1210.

(62) Delley, M. F.; Praveen, C. S.; Borosy, A. P.; Núñez-Zarur, F.; Comas-Vives, A.; Copéret, C. Olefin Polymerization on $\mathrm{Cr}(\mathrm{III}) /$ $\mathrm{SiO}_{2}$ Mechanistic Insights from the Differences in Reactivity between Ethene and Propene. J. Catal. 2017, 354, 223-230. 